\title{
Role of intra-acrosomal antigenic molecules acrin 1 (MN7) and acrin 2 (MC41) in penetration of the zona pellucida in fertilization in mice
}

\author{
D. K. Saxena, I. Tanii, K. Yoshinaga and K. Toshimori* \\ Department of Anatomy and Reproductive Cell Biology, Miyazaki Medical College, Kihara 5200, \\ Kiyotake, Miyazaki 889-1692, Japan
}

\begin{abstract}
In this study the role of two intra-acrosomal molecules, acrin 1 (MN7) and acrin 2 (MC41), during in vitro fertilization (IVF) was examined. The pertinent monoclonal antibodies mMN7 and mMC41 specifically recognize a $90 \mathrm{kDa}$ protein (acrin 1) localized to the entire acrosome and a $200 \mathrm{kDa}$ protein (acrin 2) localized to the cortex region of the anterior acrosome, respectively. Experiments were designed to assess the effects of mMN7 and mMC41 on fertilization in mice using TYH medium containing mMN7 or mMC41 at $0.0,0.025,0.05$ and $0.1 \mathrm{mg} \mathrm{ml}^{-1}$. Under these conditions, capacitated spermatozoa inseminated the cumulus-invested oocytes. Acrosome-reacted spermatozoa inseminated the zona pellucida-free oocytes. The antibodies had no effect on sperm motility and primary binding to the zona pellucida, but significantly inhibited the rate of fertilization of zona pellucida-intact oocytes in a dose-dependent manner. A significantly small number of spermatozoa remained attached to the zona pellucida at $5 \mathrm{~h}$ after insemination in the presence of mMC41. mMC41 and mMN7 antibodies did not affect the fertilization rate of zona pellucida-free oocytes. Confocal laser scanning microscopy with indirect immunofluorescence traced the effect of the monoclonal antibodies on the zona pellucida-induced acrosome reaction, and revealed that mMN7 prevented completion of acrosomal matrix dispersal, whereas mMC41 did not affect the acrosome reaction. mMC41 appeared to inhibit secondary binding or some biochemical steps on the zona pellucida after the acrosome reaction but before penetration of the zona pellucida. Thus, the intra-acrosomal antigenic molecules acrin 1 and acrin 2 are essential for distinct events before sperm penetration of the zona pellucida in mice.
\end{abstract}

\section{Introduction}

The complex process of fertilization culminates in interactions between the spermatozoon and the oocyte. Mammalian spermatozoa are highly differentiated cells consisting of a head and a flagellum. The anterior acrosome localized at the rostral region of the head is involved in the acrosome reaction and the equatorial segment is involved in membrane fusion with the oocyte (Bedford and Cooper, 1978; Wassarman, 1987; Oura and Toshimori, 1990; Yanagimachi, 1994). The molecules that are unique to the sperm head have important roles in fertilization and can elicit specific antibodies (Katsh, 1959; O'Rand, 1980; Tung et al., 1980; Eddy and O'Brien, 1994; Toshimori, 1998).

Many studies have been undertaken to identify the molecular aspects of individual gamete components involved in specific events before and after fertilization. The relationship between immunization with spermatozoa and reduced fertility is well established (Menge et al., 1979; Tung

*Correspondence.

Received 27 May 1998. et al., 1979). Furthermore, individual steps in the interaction of gametes can be blocked in vitro by using monoclonal antibodies (mAbs) directed against mature sperm components (Saling and O'Rand, 1982). The effects of specific antibodies on fertilization have been studied using a number of in vivo and in vitro assays (O'Rand, 1981; Saling and O'Rand, 1982; Naz et al., 1983, 1984; Saling and Lakoski, 1985; Samuel et al., 1987). Although the roles of many sperm molecules in fertilization have been reported and reviewed (McLeskey et al., 1998), no consensus has emerged on the precise roles of these molecules during sperm-oocyte interaction.

A number of $\mathrm{mAb}$ probes against mouse epididymal spermatozoa have been produced, for example mMN7 (Tanii et al., 1994), mMC41 (Tanii et al., 1992a,b, 1995) and mMC101 (Toshimori et al., 1995). All of these antibodies are IgG1. mMN7 recognizes a $90 \mathrm{kDa}$ protein (MN7) localized to the entire mouse acrosomal matrix and mMC41 recognizes a $200 \mathrm{kDa}$ protein (MC41) localized to the cortex region of the mouse anterior acrosomal matrix. Thus, in the present study, the names 'acrin 1' and 'acrin 2' are proposed for MN7 and MC41, respectively. Tanii et al. (1995) proposed that acrin 1 
and acrin 2 are released in different patterns from the acrosome matrix during an induced acrosome reaction. Therefore, the aim of the present study was to determine the function of acrin 1 and acrin 2 in fertilization in vitro.

\section{Materials and Methods}

\section{Animals}

Female mice (ICR strain) at 3-4 months of age were purchased from Kyudo Company (Kumamoto) and were maintained in the laboratory animal centre of Miyazaki Medical College in an automatically controlled environment ( $12 \mathrm{~h}$ light: $12 \mathrm{~h}$ dark, $20^{\circ} \mathrm{C}$ ) with free access to food and water. The procedures were in accordance with the animal welfare guidelines of the college. The animals were anaesthetized with ether and killed by cervical dislocation.

\section{Reagents, IVF culture medium and antibodies}

All organic and inorganic compounds were purchased from Nacalai Tesque Inc. (Kyoto) unless otherwise stated and were of analytical and culture grade. The modified Krebs Ringer bicarbonate solution (TYH medium; Toyoda et al., 1971) was used for gamete manipulation and fertilization throughout the study. The protein concentration was estimated by the bicinchonic acid (BCA) method according to the supplier's manual (Pierce Chemical Co., Rockford, IL).

Antibodies mMN7 and mMC41 were characterized according to Tanii et al. (1992a,b) and purified using the method described by Toshimori et al. (1998). Briefly, the antibody was purified with a protein A column (Ampure PA kit; Amersham International, Amersham), eluted with eluting buffer and three fractions of $1 \mathrm{ml}$ were collected. The concentration was estimated by the BCA method, and the peak fraction was desalted with a TYH medium preequilibrated Sephadex G 25M column (PD-10 column) to exchange binding buffer with TYH medium. Ten fractions each of $1 \mathrm{ml}$ were collected by the PD-10 column, and the $\mathrm{mAb}$ concentration was estimated. The peak fraction $(0.3-0.7$ $\mathrm{mg} \mathrm{ml}^{-1}$ peak yield) was stored at $-80^{\circ} \mathrm{C}$ until required for the IVF experiments. A mAb (mMC31) that specifically recognizes the rat sperm flagellar surface (Toshimori et al., 1992) was prepared in the same way for use as a control.

\section{Experimental design of IVF}

The IVF investigation was conducted in two groups: in one group, zona pellucida-intact (zona-intact) (cumulusinvested) oocytes were inseminated and in the second group, zona pellucida-free (zona-free) oocytes were inseminated.

Oocytes were prepared as follows. Mature female mice were induced to ovulate by consecutive intraperitoneal injections of 5 iu pregnant mares' serum gonadotrophin (PMSG) followed $48 \mathrm{~h}$ later with $5 \mathrm{iu}$ hCG. The mature unfertilized cumulus-intact oocytes were collected $13-15 \mathrm{~h}$ after administration of hCG by rupturing the oviductal ampulla under oil (dimethyl polysiloxane; Sigma Chemical Co., St Louis, MO) in IVF dishes (Falcon, \#3653).

Zona-free oocytes were prepared as follows. The zona pellucida was removed according to the method of Fann and Lee (1992) with slight modifications. Briefly, mature oocytes were collected as described earlier and treated with $0.05 \%$ $(\mathrm{w} / \mathrm{v})$ hyaluronidase in TYH medium for 5-10 min. After hyaluronidase treatment, the cumulus-free oocytes were transferred to fresh TYH medium and washed twice with TYH medium. The zona pellucida was removed from the oocytes by treatment with low-pH TYH medium ( $\mathrm{pH} 2.5)$. The zona-free oocytes were transferred to IVF dishes containing TYH medium equilibrated with $5 \% \mathrm{CO}_{2}$ in air and were incubated for at least $1 \mathrm{~h}$ at $37^{\circ} \mathrm{C}$ to allow recovery.

Before use, all oocytes were transferred to IVF dishes containing $\mathrm{TYH}$ medium equilibrated with $5 \% \mathrm{CO}_{2}$ in air for at least $2 \mathrm{~h}$ at $37^{\circ} \mathrm{C}$.

Spermatozoa were collected from the cauda epididymides of mature male mice. The distal portion of the epididymis was cut using a blade, and a dense sperm mass was squeezed out.

\section{Capacitation, induction of the acrosome reaction and insemination}

Spermatozoa were allowed to disperse into $400 \mu \mathrm{T} \mathrm{TYH}$ medium under oil in an IVF dish. The spermatozoa were diluted to a final concentration of $2 \times 10^{5}$ spermatozoa $\mathrm{ml}^{-1}$ in TYH medium, and were incubated for $2 \mathrm{~h}$ at $37^{\circ} \mathrm{C}$ in $5 \% \mathrm{CO}_{2}$ for capacitation. The capacitated spermatozoa were used for insemination.

The acrosome reaction was induced by zona pellucida protein according to the method of Fan and Lee (1992). The zonae pellucidae of 1000-1500 oocytes, from which the cumulus cells had been removed as described earlier, were dissolved in $100 \mu \mathrm{l}$ low-pH TYH medium ( $\mathrm{pH} 2.5)$ in a $0.5 \mathrm{ml}$ tube and centrifuged for $5 \mathrm{~min}$ at $150 \mathrm{~g}$. The supernatant was collected, and the $\mathrm{pH}$ was adjusted to 7.2. The solution containing zona pellucida protein was stored at $-80^{\circ} \mathrm{C}$ until use for induction of the acrosome reaction. Its efficacy was determined at concentrations of zona pellucida protein equivalent to $0,1,2$ and 4 zonae pellucidae $\mu l^{-1}$. Spermatozoa were collected and capacitated as described earlier. After capacitation for $60 \mathrm{~min}$, the acrosome reaction was induced in TYH medium containing 0.0 (control) or $0.1 \mathrm{mg} \mathrm{m}^{-1}$ of either mMN7 or mMC41 by adding zona pellucida protein equivalent to 2 zonae pellucidae $\mu l^{-1}$ to $20 \mu \mathrm{l}$ sperm suspension $\left(2 \times 10^{5}\right.$ spermatozoa $\left.\mathrm{ml}^{-1}\right)$ and incubating at $37^{\circ} \mathrm{C}$ for $30 \mathrm{~min}$ (Lakoski et al., 1988). The acrosomal status was also determined at 10 and $60 \mathrm{~min}$ after incubation with zona pellucida protein by indirect immunofluorescence light microscopy and confocal laser scanning microscopy (see below).

A 2-10 $\mu$ l volume of capacitated spermatozoa was used to inseminate the zona-intact oocytes in TYH containing either mMN7 or mMC41 at 0.0 (control), $0.025,0.05$ or $0.1 \mathrm{mg} \mathrm{ml}^{-1}$. The same volume of the acrosome-reacted spermatozoa was used to inseminate the zona-free oocytes in TYH containing either mMN7 or mMC41 at 0.0 (control) or $0.1 \mathrm{mg} \mathrm{ml}^{-1}$. The 
final concentration of spermatozoa was adjusted to approximately $4 \times 10^{4}$ spermatozoa ml-1.

\section{Assessment of sperm motility and IVF events}

Sperm motility and fertilization were monitored by a videotape recorder connected to an inverted microscope (IM type, Olympus, Tokyo) through a charge coupled device (CCD) camera (Model KP-M1, Hitachi Denshi Ltd, Tokyo). The percentage of motile spermatozoa was estimated by the hanging drop preparation method (Mastroianni and Manson, 1963).

Inseminated oocytes were incubated for $1,2,5$ or $24 \mathrm{~h}$ at $37^{\circ} \mathrm{C}$ in $5 \% \mathrm{CO}_{2}$. The videotape recorder system recorded the effect of the mAbs on sperm binding, sperm penetration through the zona pellucida, pronucleus formation and twocell embryo formation. The mAbs were used at a concentration of $0.1 \mathrm{mg} \mathrm{ml}^{-1}$ in each experiment, since the effects were stable at this concentration.

Primary sperm binding was assessed as follows. Oocytes were recovered and transferred to a drop of $4 \%(\mathrm{w} / \mathrm{v})$ paraformaldehyde at $1.5 \mathrm{~h}$ after insemination. The number of spermatozoa bound at the focus plane of the maximal diameter of the zona pellucida was examined under an inverted phase-contrast microscope (Olympus) and was photographed before washing.

Secondary sperm binding was assessed as follows. The sample (oocytes and zygotes after IVF) was collected at 1.5 and $5 \mathrm{~h}$ after insemination, washed three times in PBS and transferred to a drop of $4 \%(\mathrm{w} / \mathrm{v})$ paraformaldehyde. After this procedure, only spermatozoa that were bound strongly to the zona pellucida remained. The number of spermatozoa bound at the focus plane of the maximal diameter of the zona pellucida was examined under an inverted phasecontrast microscope (Olympus) and the acrosome status was determined by indirect immunofluorescence light microscopy as described below.

Fertilization was determined by the presence of pronuclei under a phase-contrast microscope at $5 \mathrm{~h}$ after insemination. Two-cell embryo formation was also determined at $24 \mathrm{~h}$ after insemination (data not shown).

\section{Assessment of acrosome reaction (acrosomal status)}

mMN7 and mMC41 stained the acrosome of both unfixed and paraformaldehyde-fixed spermatozoa. Since both acrin 1 and acrin 2 are acrosomal matrix proteins, these antigenic molecules were exposed after fixation and drying. The molecules gradually dispersed during the acrosome reaction and were not present on completely reacted spermatozoa. Hence mMN7 and mMC41 were used to determine the acrosomal status by indirect immunofluorescence using confocal laser scanning microscopy (model TCS 4D, LEICA, Nussloch) and a fluorescence apparatus-equipped light microscope (BX-50 type, Olympus). Spermatozoa were classified as follows: stage $\mathrm{I}$, intact or acrosome-unreacted spermatozoa; stage II, spermatozoa undergoing the acrosome reaction (early stage of acrosomal matrix dispersal); stage III, spermatozoa undergoing the acrosome reaction (later stage of acrosomal matrix dispersal); stage IV, negative spermatozoa considered to be completely acrosome-reacted.

\section{Indirect immunofluorescence and immunocytochemistry}

Indirect immunofluorescence and immunocytochemistry were performed to determine whether immunoreactive acrin 1 and acrin 2 molecules remained in the acrosome-reacted spermatozoa and whether mMN7 and mMC41 would crossreact with the oocyte. Oocytes and the spermatozoa that had undergone the acrosome reaction were washed three times. Thereafter, they were incubated with the primary antibody mMN7 or mMC41 for $1 \mathrm{~h}$, washed three times, and incubated with the second antibody, goat fluorescein isothiocyanate (FITC)-conjugated anti-mouse IgG and IgM (Biosource International, Camarillo, CA) for $30 \mathrm{~min}$. The samples were washed three times and examined by both confocal laser scanning microscopy and the fluorescence apparatus-equipped light microscope mentioned earlier.

\section{Statistical analysis}

Each experiment was performed three to eight times depending on the purpose. The data were analysed by Student's $t$ test (Tables 1 and 4) and the chi-squared test (Tables 2, 3 and 4). Probability values less than $5 \%$ were considered significant.

\section{Results}

\section{Sperm motility}

More than $70 \%$ of the spermatozoa remained motile in all experimental groups treated with mMN7 and mMC41, as well as in the control groups treated with TYH medium only or with $\mathrm{mMC} 31$.

\section{Sperm binding}

Before the sperm-oocyte complexes were washed, 19.3-22.1 spermatozoa (average of all groups) were attached to the zona pellucida at $1.5 \mathrm{~h}$ after insemination. The differences among the number of spermatozoa bound to the zona pellucida in the presence of the mAbs (mMN7 and mMC41) and in the control groups were not significant, indicating that primary binding was not affected by the mAbs (Fig. 1a; Table 1). After three washes, 4.8-6.2 spermatozoa (average of all groups) remained attached to the zona pellucida, indicating strong or secondary binding (Table 1). Thereafter, as the time of incubation increased, the number of bound spermatozoa decreased markedly in the presence of $\mathrm{mMC} 41$, even without washing. At $5 \mathrm{~h}$ after insemination, a very low number of spermatozoa (an average of 0.8 spermatozoa per oocyte) remained attached to 
Table 1. Effect of monoclonal antibodies mMN7 and mMC41 on sperm binding to zona pellucida of mice

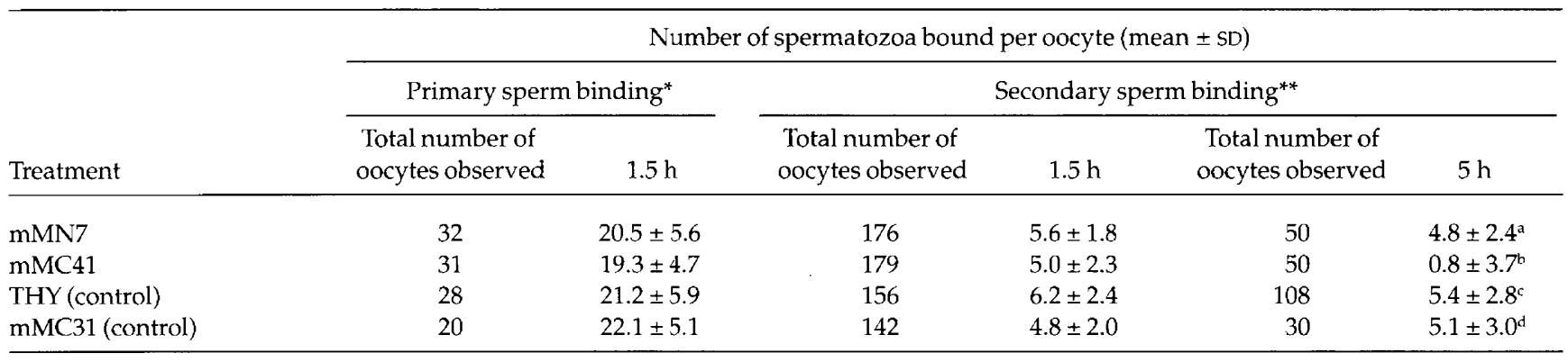

Experiments were conducted three times.

* Observation was done without washing.

** Observation was done after washing three times.

Concentration of monoclonal antibodies: $0.1 \mathrm{mg} \mathrm{ml}^{-1}$.

$P<0.001$ : b versus a, $c, d$.

Table 2. Effect of monoclonal antibodies mMN7 and mMC41 on fertilization of mouse zona pellucida-intact oocytes

\begin{tabular}{lccc}
\hline Treatment & $\begin{array}{c}\text { Antibody concentration } \\
\left(\mathrm{mg} \mathrm{ml}^{-1}\right)\end{array}$ & $\begin{array}{c}\text { Total number of } \\
\text { oocytes observed }\end{array}$ & $\begin{array}{r}\text { Percentage pronucleus } \\
\text { formation (mean } \pm \text { SD) }\end{array}$ \\
\hline mMN7 & 0.1 & 106 & $3.2 \pm 4.1^{\mathrm{a} 1}$ \\
& 0.05 & 108 & $14.5 \pm 6.1^{\mathrm{a} 2}$ \\
mMC41 & 0.025 & 93 & $21.7 \pm 7.2^{\mathrm{a} 3}$ \\
& 0.1 & 59 & $3.5 \pm 3.8^{\mathrm{b} 1}$ \\
TYH (control) & 0.05 & 55 & $11.6 \pm 9.0^{\mathrm{b} 2}$ \\
mMC31(control) & 0.025 & 64 & $19.6 \pm 11.0^{\mathrm{b} 3}$ \\
\hline
\end{tabular}

Experiments were conducted four times.

$P<0.001$ : a1-a3, b1-b3 in comparison with both $\mathrm{c} 1$ and $c 2$

Table 3. Effect of monoclonal antibodies mMN7 and mMC41 on fertilization of mouse zona pellucida-free oocytes

\begin{tabular}{lcc}
\hline Treatment & Total number of oocytes observed & Percentage pronucleus formation (mean \pm SD) \\
\hline mMN7 & 68 & $87.1 \pm 3.8$ \\
mMC41 & 57 & $85.9 \pm 6.3$ \\
TYH (control) & 57 & $86.9 \pm 3.5$ \\
\hline
\end{tabular}

Experiments were conducted four times.

Concentration of monoclonal antibodies: $0.1 \mathrm{mg} \mathrm{ml}^{-1}$.

the zona pellucida in the mMC41 group compared with the control (5.1-5.4 spermatozoa per oocyte) and mMN7 (4.8 spermatozoa per oocyte) groups (Table 1). The difference between the mMC41 group and the other groups was significant $(P<0.001)$.

\section{Fertilization rate in the zona-intact experiment}

Pronucleus formation was blocked in a dose-dependent manner; the fertilization rate was $3-22 \%$ and $4-20 \%$ in the mMN7 and mMC41 groups, respectively, compared with $70-71 \%$ in the control group (Fig. 1b,c; Table 2). The difference between the experimental groups and the control group was significant $(P<0.001)$.
Two-cell embryo formation was also blocked significantly, showing a trend similar to that of pronucleus formation in the presence of $\mathrm{mAbs}$. The fertilization rate was $2-11 \%$ in the mMN7 and mMC41 groups compared with $70-82 \%$ in the control $(P<0.001)$.

\section{Fertilization rate in the zona-free experiment}

The effect of $m A b s$ on the ability of reacted spermatozoa to bind to the oolemma was determined using zona-free oocytes. The oocytes incorporated the acrosome-reacted spermatozoa and developed to the pronuclear and two-cell embryonic stage in both the mMN7 and mMC41 groups as well as in the control group. The fertilization rate was more 
Table 4. Effect of monoclonal antibodies $\mathrm{mMN7}$ and $\mathrm{mMC} 41$ on mouse zona pellucida-induced acrosome reaction in vitro

\begin{tabular}{|c|c|c|c|c|c|}
\hline $\begin{array}{l}\text { Spermatozoa } \\
\text { exposed to ZP } \\
\text { protein for } 30 \mathrm{~min} \\
\text { in presence of }\end{array}$ & $\begin{array}{l}\text { First antibody } \\
\text { used for indirect } \\
\text { mmunofluorescence }\end{array}$ & $\begin{array}{c}\text { Total number of } \\
\text { spermatozoa } \\
\text { observed }\end{array}$ & $\begin{array}{l}\text { Percentage intact } \\
\text { spermatozoa } \\
\text { (mean } \pm \mathrm{SD} \text { ) }\end{array}$ & $\begin{array}{c}\text { Percentage } \\
\text { spermatozoa during } \\
\text { acrosome reaction } \\
\text { (mean } \pm \mathrm{SD})\end{array}$ & $\begin{array}{l}\text { Percentage } \\
\text { reacted } \\
\text { spermatozoa } \\
(\text { mean } \pm \mathrm{SD})\end{array}$ \\
\hline $\begin{array}{r}\mathrm{mMN}^{*} \\
(n=3)\end{array}$ & mMN7 & 300 & $13.6 \pm 10.0$ & $66.0 \pm 1.7^{\mathrm{a}}$ & $20.0 \pm 10.0^{e}$ \\
\hline $\begin{array}{l}\text { TYH (control) } \\
\quad(n=3)\end{array}$ & mMN7 & 300 & $9.3 \pm 6.4$ & $40.3 \pm 15.0^{b}$ & $50.3 \pm 14.0^{f}$ \\
\hline $\begin{array}{l}\mathrm{TYH}(\text { control })^{* *} \\
(n=2)\end{array}$ & mMC41 & 200 & $20.5 \pm 0.7$ & $31.0 \pm 9.8^{\mathrm{d}}$ & $48.0 \pm 8.4^{h}$ \\
\hline $\begin{array}{l}\text { Spermatozoa capacitated } \\
\text { without exposure to } \mathrm{ZP} \\
\text { protein }(n=3)\end{array}$ & mMN7 & 200 & $67.15 \pm 15.0$ & $13.5 \pm 12.0$ & $22.0 \pm 4.5$ \\
\hline
\end{tabular}

$\mathrm{ZP}$, zona pellucida.

Concentration of monoclonal antibodies: $0.1 \mathrm{mg} \mathrm{ml}^{-1}$.

$P<0.001$ : a versus $b$, e versus $\mathrm{f}$ by Student's $t$ test; $\mathrm{mMN}^{*}$ versus $\mathrm{TYH}^{*}$ by chi-squared test.

Not significant: $c$ versus $d$, $g$ versus $h$ by Student's $t$ test; $m M N 41^{* *}$ versus $\mathrm{TYH}^{* *}$ by chi-squared test.

than $85 \%$ in all groups (Table 3 ) and there were no significant differences.

\section{Indirect immunofluorescence}

Both mMN7 and mMC41 failed to crossreact with oocytes when examined by indirect immunofluorescence using confocal laser scanning microscopy (Fig. 2). Since mMN7 and mMC41 significantly inhibited the fertilization of zonaintact oocytes, further investigations were conducted to determine the precise point of the inhibition.

\section{Localization of acrin 1 and acrin 2 on mature spermatozoa from the cauda epididymidis and on capacitated and acrosome-reacted spermatozoa}

Acrin 1 and acrin 2 molecules were localized to the entire acrosome and to the cortex region of the anterior acrosome on spermatozoa from the cauda epididymidis and capacitated spermatozoa, respectively (Fig. $3 a, b$, and $i, j$ ). These molecules were gradually released from the acrosome during the zona pellucida-induced acrosome reaction (Fig. $3 c-f)$ and were not present on the completely reacted spermatozoa, as confirmed by indirect immunofluorescence (Fig. 3g,h).

\section{Induction of acrosome reaction by zona pellucida protein}

The ability of the zona pellucida to induce the acrosome reaction was assessed. The zona pellucida protein induced the acrosome reaction in a dose-dependent manner; $17,52,53$ and $67 \%$ of the spermatozoa underwent the acrosome reaction at $0,1,2$ and 4 zonae pellucidae $\mu l^{-1}$, respectively.

The effects of mMN7 and mMC41 on the zona pellucidainduced acrosome reaction were investigated. The samples were assessed by indirect immunofluorescence using confocal laser scanning microscopy at $30 \mathrm{~min}$ after induction of the acrosome reaction. mMN7 significantly inhibited the acrosome reaction. Only $20 \%$ of the spermatozoa were completely acrosome-reacted (stage IV) (Fig. 3g,h) when the acrosome reaction was induced in the presence of $0.1 \mathrm{mg}$ mMN7 $\mathrm{ml}^{-1}$, whereas 50 and $45 \%$ of the spermatozoa completed the acrosome reaction in the absence of $\mathrm{mAbs}$ and in the presence of $0.1 \mathrm{mg} \mathrm{mMC} 41 \mathrm{ml}^{-1}$, respectively. The percentage of acrosome-reacted spermatozoa in the presence of mMN7 $(20 \%)$ was almost equal to the percentage of spontaneously acrosome-reacted spermatozoa after capacitation. In contrast, the percentage of spermatozoa undergoing stage II and III acrosome reactions (Fig. $3 \mathrm{c}-\mathrm{f}$ ) increased significantly $(P<0.001)$ in the presence of mMN7 $(66 \%)$ compared with the control $(40 \%)$ (Table 4$)$.

\section{Acrosomal status of spermatozoa bound to zona pellucida}

Between 10 and 15 oocytes that had spermatozoa bound to the zona pellucida were collected from all three groups (TYH medium only, mMN7 and mMC41) at $1.5 \mathrm{~h}$ after insemination, and were assessed by indirect immunofluorescence with mMN7 or mMC41. In the presence of mMN7, most of the bound spermatozoa were positive, and various staining patterns (Fig. 2) were observed indicating that acrosomal components including acrin 1 were not dispersed completely during the acrosome reaction. In contrast, none of the spermatozoa that was bound to the visible plane of the zona pellucida in the control group (TYH medium only) or in the presence of mMC41 was positive.

\section{Discussion}

Since many spermatozoa bound to the zona pellucida surface before washing in all groups, mMN7 and mMC41 did not appear to influence sperm motility or initial recognition and primary binding to the zona pellucida. This 

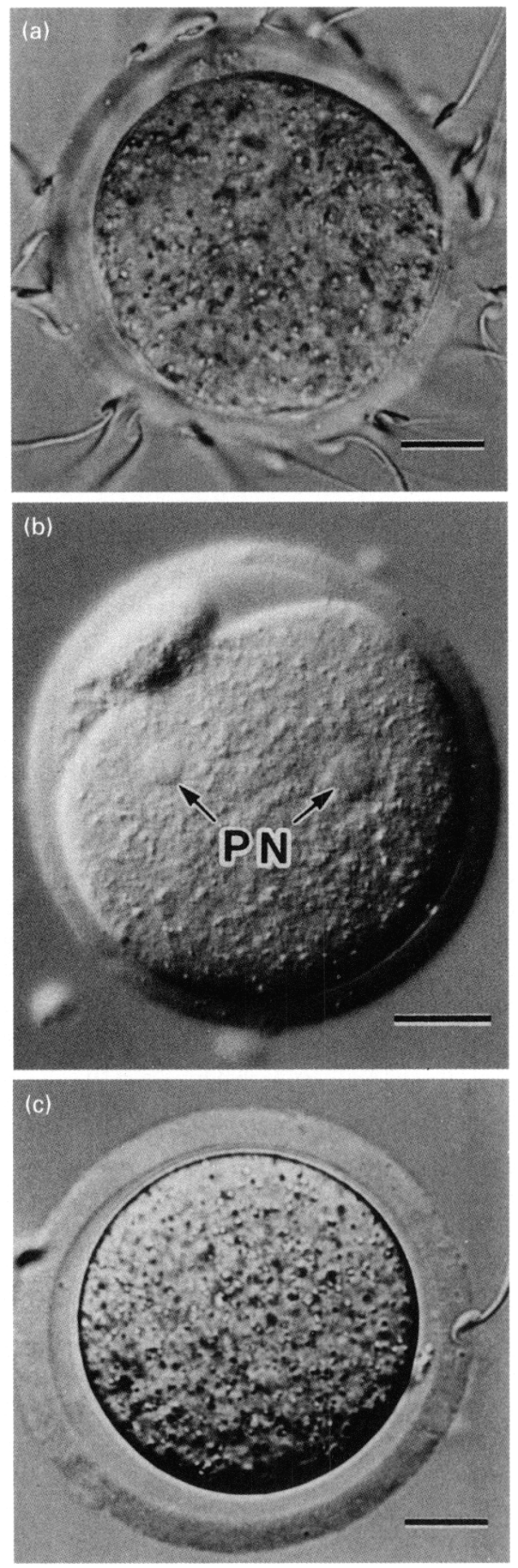

Fig. 1. Light micrographs from the zona pellucida-intact experiment. Mouse oocytes or zygotes were recovered at (a) $1.5 \mathrm{~h}$ and $(b, c) 5 \mathrm{~h}$ after insemination. (a) Primary binding in the presence of monoclonal antibody mMN7. Before washing, many spermatozoa bound to the surface of the zona pellucida. (b) Control (TYH medium). The inseminated oocytes have developed to the pronuclear stage. (c) In the presence of mMN7, the inseminated oocytes failed to develop to the pronuclear stage. Since the samples were washed vigorously to obtain good images, most of the spermatozoa bound to the zona pellucida surface had detached in (b) and (c). PN, pronucleus. Scale bars represent (a,c) $22 \mu \mathrm{m}$ and (b) $30 \mu \mathrm{m}$.
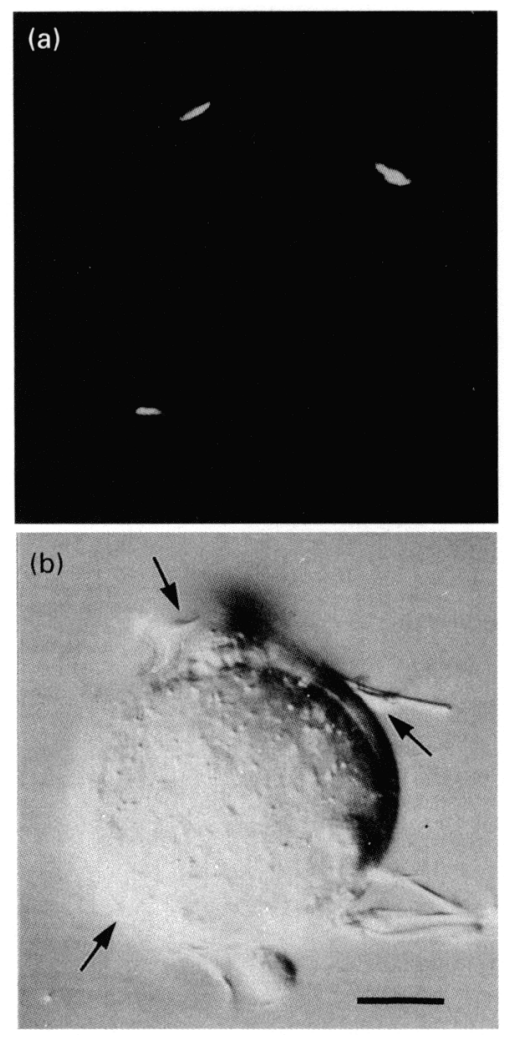

Fig. 2. Indirect immunofluorescence image taken by confocal laser scanning microscopy. Spermatozoa attached to the surface of the zona pellucida in the presence of the monoclonal antibody mMN7 at $1.5 \mathrm{~h}$ after insemination. (a) The acrosome is strongly stained, but the oocyte surface is negative. (b) Bright-field image corresponding to (a). Arrows indicate the sperm heads. Scale bar represents $15 \mu \mathrm{m}$.

is probably because acrin 1 and acrin 2 are intra-acrosomal molecules (Tanii et al., 1992a, 1994) and so are not exposed before the acrosome reaction.

The results of the present study showed that both mMN7 and mMC41 significantly inhibited fertilization of zonaintact oocytes in a dose-dependent manner, but did not influence the fertilization of zona-free oocytes. These findings indicate that acrin 1 and 2 are involved in the sperm-zona pellucida interaction before or during penetration of the zona pellucida. Before penetration, the spermatozoon recognizes and attaches to molecules, such as the O-linked carbohydrate protein of ZP3, the complementary protein molecules of which interact with molecules on the surface of the spermatozoon to induce the acrosome reaction. The acrosomal molecule, for example the tyrosine kinase-linked receptor or the protein $\mathrm{sp56}$, binds to, or interacts with, components of ZP3 to elicit intracellular signals (Leyton et al., 1992; Wassarman, 1992; Cheng et al., 1994; Yanagimachi, 1994; Olds-Clarke, 1996). In contrast, acrosome-reacted spermatozoa need to remain tightly bound to the surface of the zona pellucida with ZP2 molecules, and this strong binding is often referred to as secondary binding (Yanagimachi, 1994). Proacrosin, PH20 and some other acrosomal molecules, which are released after the acrosome reaction, are involved in secondary binding (Primakoff, 1994; 

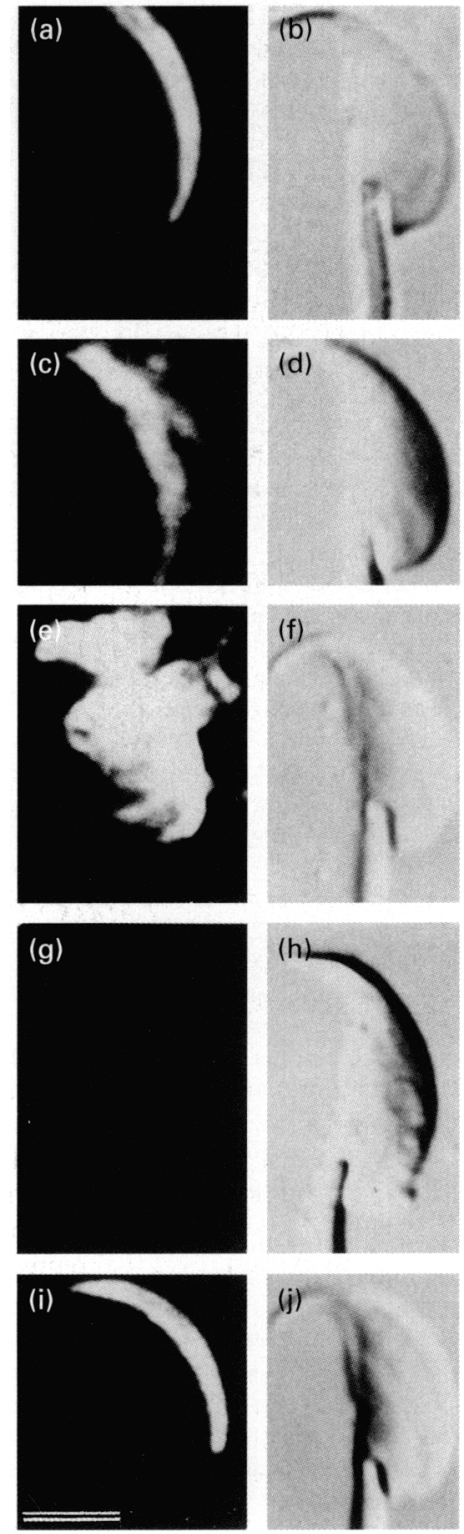

Fig. 3. Representative pairs of images of the acrosome reaction in mice; $(a, c, e, g, i)$ indirect immunofluorescence images taken by confocal laser scanning microscopy; $(b, d, f, h, j)$ corresponding brightfield images. Monoclonal antibodies $(a-h) m M N 7$ and $(i, j)$ mMC41 were used. $(a, b)$ Capacitated spermatozoa with intact acrosome (stage I); (c,d) spermatozoa during the acrosome reaction (stage II); $(\mathrm{e}, \mathrm{f})$ spermatozoa during the acrosome reaction (stage III); $(\mathrm{g}, \mathrm{h})$ completely reacted spermatozoa (stage IV); (i,j) capacitated spermatozoa with intact acrosome. Scale bar represents $3 \mu \mathrm{m}$.

Topfer-Petersen and Calvete, 1995). Sperm penetration through the zona pellucida is thought to be a combined process of vigorous sperm motility (Wakayama et al., 1996) and biochemical interactions between molecules of the zona pellucida and enzymatically active sperm components such as acrosin (Wassarman, 1992; Topfer-Petersen and Calvete, 1995). Tanii et al. (1995) proposed that MN7 (acrin 1) and MC41 (acrin 2) were gradually dispersed via different mechanisms during the acrosome reaction. It is suggested that mMN7 and mMC41 have different effects on the biochemical interactions between the molecules of the zona pellucida and the sperm components. Thus mMN7 and mMC41 might influence the dispersal of the acrosomal matrix and secondary binding, respectively, both of which inhibit sperm penetration of the zona pellucida. Similar types of inhibition by anti-sperm antibodies have been reported in other species including guinea-pigs (Yanagimachi et al., 1981; Hunnicutt et al., 1996), rabbits (Naz et al., 1983), sea urchins (Trimmer et al., 1985), mice (Saling, 1986; Kawai et al., 1993), rats (Diasalves et al., 1995), hamsters (Kito and Bavister, 1996), cows (Coonrod et al., 1996) and humans (Shibahara et al., 1993; Ruiz èt al., 1998).

In this study, the effects of mMN7 and mMC41 on the zona pellucida-induced acrosome reaction and on secondary binding were examined to evaluate the mechanism of the inhibition of sperm penetration through the zona pellucida. The results show that mMN7 inhibited completion of the acrosome reaction. Although the percentage of intermediate stage (stage II and III) spermatozoa increased and was significantly high in the presence of mMN7, the percentage of completely reacted spermatozoa (stage VI) remained low, and was almost equal to that of spontaneously reacted spermatozoa after capacitation (that is, without induction of the acrosome reaction by the zona pellucida). This result also implies that mMN7 blocks the process during the acrosome reaction. Such a step may be closely related to the process of enzymatic action during dispersal of the acrosomal components, which presumably inhibits completion of the acrosome reaction. Similar inhibition of dispersal of the acrosomal matrix has been reported in knockout mice lacking the acrosin protease activity-related gene (Yamagata et al., 1998). Evaluation of the status of the acrosome reaction was easier with confocal laser scanning microscopy compared with conventional fluorescence light microscopy, especially when tomographic images were analysed at high magnification.

Since mMC41 did not influence the zona pellucidainduced acrosome reaction, acrin 2 could be involved in events that occur after the acrosome reaction, but before penetration through the zona pellucida. Primary binding of spermatozoa to the zona pellucida remained unaffected in the presence of mMC41. However, a significantly small number of spermatozoa remained firmly attached to the zona pellucida at $5 \mathrm{~h}$ after insemination in the presence of mMC41 compared with the control. Thus, acrin 2 appears more likely to participate in secondary binding to molecules of the zona pellucida, such as ZP2, or in biochemical steps that are necessary for penetration of the zona pellucida, like acrosin. However, acrosin was not essential for sperm penetration of the zona pellucida in knockout mice lacking the acrosin-related gene (Baba et al.,1994). Thus, acrin 2 may be a new candidate to participate in secondary binding, at least in mice.

The findings of the present study indicate that acrin 1 and acrin 2 molecules are involved in different steps of the sperm-zona pellucida interaction before penetration through the zona pellucida, and both mMN7 and mMC41 seem to be effective blockers of fertilization. Since the precise molecular mechanism of inhibition of the sperm-zona pellucida interaction and sperm penetration through the 
zona pellucida remains unclear, it is of interest to conduct further experiments using specific probes such as mMN7 and $\mathrm{mMC41}$ in combination with other useful techniques such as gene knockout mice. Since acrin 1 is also well preserved in human spermatozoa (Tanii et al., 1994), it is a good candidate for the study of contraception in humans.

The authors are grateful to Y. Tuzuki (Miyazaki University) for technical advice, Y. Fujii for excellent technical assistance and $\mathrm{H}$. Kiyotake for the word processing. This study was supported by a grant from the Ministry of Education, Science, Sports and Culture of Japan and a grant-in-aid for scientific research to $\mathrm{K}$. Toshimori (08670025 and 09670021).

\section{References}

Baba T, Azuma S, Kashiwabara S and Toyoda Y (1994) Sperm from mice carrying a targeted mutation of the acrosin gene can penetrate the oocyte zona pellucida and affect fertilization Journal of Biological Chemistry 26931 845-31 849

Bedford JM and Cooper GW (1978) Membrane fusion events in the fertilization of vertebrate eggs. In Membrane Fusion Vol. 5 pp 65-125 Eds G Poste and GL Nicolson. Biomedical Press, Elsevier/North Holland Amsterdam

Cheng A, Le T, Palacios M, Bookbinder LH, Wassarman PM, Suzuki F and Bleil JD (1994) Sperm-egg recognition in the mouse: characterization of sp56, a sperm protein having specific affinity for ZP3 journal of Cell Biology $125867-878$

Coonrod SA, Herr JC and Westhusin ME (1996) Inhibition of bovine fertilization in vitro by antibodies to SP-10 Journal of Reproduction and Fertility $107287-297$

Diasalves MS, Martins MS and Pena SDJ (1995) Monoclonal antibody against a 52K sperm surface protein inhibits sperm-zona pellucida interactions in the rat Journal of Experimental Zoology 272 123-133

Eddy EM and O'Brien DA (1994) The spermatozoon. In The Physiology of Reproduction 2nd Edn pp 29-77 Eds E Knobil and JD Neill. Raven Press, New York

Fann C-H and Lee C-Y (1992) Monoclonal antibodies affecting sperm-zona binding and/or zona-induced acrosome reaction Journal of Reproductive Immunology 21 175-187

Hunnicutt GR, Primakoff P and Myles DG (1996) Sperm surface protein PH20 is bifunctional: one activity is a hyaluronidase and a second, distinct activity is required in secondary sperm-zona binding Biology of Reproduction $\mathbf{5 5} 80-86$

Katsh S (1959) Infertility in female guinea pigs induced by injection of homologous sperm American Journal of Obstetrics and Gynecology 78 $276-278$

Kawai Y, Ohnishi S, Uehara M, Hama T and Mayumi T (1993) Effect of a monoclonal anti-sperm antibody (A-1) on in vitro fertilization in the mouse Biological and Pharmaceutical Bulletin 16 116-119

Kito S and Bavister BD (1996) Kinetics of sperm penetration and fertilization in vitro in hamster follicular and oviductal ova Journal of Experimental Zoology 274 373-383

Lakoski KA, Carron CP, Cabot CL and Saling PM (1988) Epididymal maturation and the acrosome reaction in mouse sperm: response to zona pellucida develops coincident with modification of M42 antigen Biology of Reproduction 38 221-233

Leyton L, LeGuen P, Bunch D and Saling PM (1992) Regulation of mouse gamete interaction by a sperm tyrosine kinase Procedings National Academy of Sciences USA 8911 692-11 695

McLeskey SB, Dowds C, Carballada R, White RR and Saling PM (1998) Molecules involved in mammalian sperm-egg interaction International Review of Cytology 177 57-113

Mastroianni L and Manson WA (1963) Collection of monkey semen by electroejaculation Proceedings of the Society for Biology and Medicine 112 $1025-1027$

Menge AC, Peegel H and Riolo ML (1979) Sperm fractions responsible for immunologic induction of pre- and postfertilization infertility in rabbits Biology of Reproduction 20 931-937
Naz RK, Saxe JM and Menge AC (1983) Inhibition of fertility in rabbits by monoclonal antibodies against sperm Biology of Reproduction 28 249-254

Naz RK, Alexander NJ and Isahakia M (1984) Monoclonal antibody to a human germ cell membrane glycoprotein that inhibits fertilization Science $225342-344$

Olds-Clarke P (1996) How does poor motility alter sperm fertilizing ability? Journal of Andrology 17 183-186

O'Rand MG (1980) Antigens of spermatozoa and their environment. In Immunological Aspects of Infertility and Fertility Regulation pp 155-171 Eds DS Dhindsa and CFB Schumacher. Elsevier, North Holland, New York

O'Rand MG (1981) Inhibition of fertility and sperm-zona binding by antiserum to the rabbit sperm membrane autoantigen RSA-1 Biology of Reproduction 25 621-628

Oura C and Toshimori K (1990) Ultrastructural studies on the fertilization of mammalian gametes International Review of Cytology 122 105-151

Primakoff $\mathbf{P}$ (1994) Sperm proteins being studied for use in a contraceptive vaccine American Journal of Immunology 31 208-210

Ruiz CM, Duquenne C, Tretion D, Lefevre A and Finaz C (1998) SOB3, a human sperm protein involved in zona pellucida binding: physiological and biochemical analysis and purification Molecular Reproduction and Development 49 286-297

Saling PM (1986) Mouse sperm antigens that participate in fertilization. IV. A monoclonal antibody prevents zona penetration by inhibition of the acrosome reaction Developmental Biology 117 511-519

Saling PM and Lakoski KA (1985) Mouse sperm antigens that participate in fertilization II. Inhibition of sperm penetration through the zona pellucida using monoclonal antibodies Biology of Reproduction 33 527-536

Saling PM and O'Rand MG (1982) Anti-mouse sperm antiserum. Fertility inhibition in vitro and preliminary antigen identification Journal of Andrology 3434-439

Samuel T, Soffer $Y$ and Caspi E (1987) Sperm-egg penetration of human spermatozoa treated with various rabbit antisera to human sperm antigens Clinical and Experimental Immunology $67454-459$

Shibahara H, Burkman LJ, Isojima S and Alexander NJ (1993) Effects of sperm-immobilizing antibodies on sperm-zona pellucida tight binding Fertility and Sterility $60533-539$

Tanii I, Toshimori K, Araki S and Oura C (1992a) Appearance of an intraacrosomal antigen during the terminal step of spermiogenesis in the rat $\mathrm{Cell}$ and Tissue Research 267 203-208

Tanii I, Toshimori K, Araki S and Oura C (1992b) Extra-Golgi pathway of an acrosomal antigen during spermiogenesis in the rat Cell and Tissue Research 270 451-457

Tanii I, Araki S and Toshimori K (1994) Intra-acrosomal organization of a 90kilodalton antigen during spermiogenesis in the rat Cell and Tissue Research $27761-67$

Tanii I, Araki S and Toshimori K (1995) Further characterization of intraacrosomal MN7 and MC41 antigens, with special reference to immunoelectron microscopic comparison of releasing process during the acrosome reaction in the mouse Acta Histochemica et Cytochemica 28 447-452

Topfer-Petersen E and Calvete JJ (1995) Molecular mechanisms of the interaction between sperm and zona pellucida in mammals - study on the pig International journal of Andrology 18 20-26

Toshimori K (1998) Maturation of mammalian spermatozoa; modifications of the acrosome and plasma membrane leading to fertilization Cell and Tissue Research 293 177-187

Toshimori K, Tanii I, Araki S and Oura C (1992) A rat sperm flagellar surface antigen that originates in the testis and is expressed on the flagellar surface during epididymal transit Molecular Reproduction and Development 32 399-408

Toshimori K, Tanii I and Araki S (1995) Intra-acrosomal 155,000 dalton protein increases the antigenicity during mouse sperm maturation in the epididymis: a study using a monoclonal antibody MC101 Molecular Reproduction and Development $\mathbf{4 2}$ 72-79

Toshimori K, Saxena DK, Tanii I and Yoshinaga K (1998) An MN9 antigenic molecule, equatorin, is required for successful sperm-oocyte fusion in mice Biology of Reproduction 59 22-29

Toyoda Y, Yokoyama M and Hoshi T (1971) Studies on the fertilization of mouse eggs in vitro. Japanese Journal of Animal Reproduction 16 147-157

Trimmer JS, Trowbridge, IS and Vacquier VD (1985) Monoclonal antibody to a membrane glycoprotein inhibits the acrosome reaction and $\mathrm{Ca}^{2+}$ and $\mathrm{H}^{+}$ fluxes of sea urchin sperm Cell $40697-703$

Tung KSK, Han LB and Evan AP (1979) Differentiation autoantigen of testicular cells and spermatozoa in the guinea pig Developmental Biology 68 224-238 
Tung KSK, Okada A and Yanagimachi R (1980) Sperm autoantigens and fertilization I. Effects of antisperm autoantibodies on rouleaux formation, viability, and acrosome reaction of guinea-pig spermatozoa Biology of Reproduction 23 877-886

Wakayama T, Ogura A, Suto J, Matsubara $Y$, Kurohmaru M, Hayashi $Y$ and Yanagimachi R (1996) Penetration by field vole spermatozoa of mouse and hamster zonae pellucidae without acrosome reaction Journal of Reproduction and Fertility 107 97-102

Wassarman PM (1987) Early events in mammalian fertilization Annual Review of Cell Biology 3 109-142
Wassarman PM (1992) Mouse gamete adhesion molecules Biology of Reproduction 46 186-191

Yamagata K, Maruyama K, Okabe M, Toshimori K and Baba T (1998) Acrosin accelerates the dispersal of sperm acrosomal proteins during acrosome reaction Journal of Biological Chemistry $27310470-10474$

Yanagimachi R (1994) Mammalian fertilization. In The Physiology of Reproduction 2nd Edn pp 189-317 Eds E Knobil and JD Neill. Raven Press, New York

Yanagimachi R, Okada A and Tung KSK (1981) Sperm autoantigens and fertilization II. Effects of anti-guinea pig sperm autoantibodies on sperm-ovum interactions Biology of Reproduction 24 512-518 